\title{
Micorriza arbuscular em cupuaçu e pupunha cultivados em sistema agroflorestal e em monocultivo na Amazônia Central
}

\author{
José Pereira da Silva Junior ${ }^{(1)}$ e Elke Jurandy Bran Nogueira Cardoso(2)
}

\begin{abstract}
(1)Embrapa Amazônia Ocidental, Caixa Postal 319, CEP 69011-970 Manaus, AM. E-mail: jpereira@cpaa.embrapa.br (2)Universidade de São Paulo, Escola Superior de Agricultura Luiz de Queiroz, Dep. de Solos e Nutrição de Plantas, Caixa Postal 9, CEP 13418-900 Piracicaba, SP. E-mail: ejbncard@esalq.usp.br
\end{abstract}

\begin{abstract}
Resumo - O objetivo deste trabalho foi avaliar a colonização micorrízica arbuscular em pupunha (Bactris gasipaes Kunth) e cupuaçu (Theobroma grandiflorum (Willd ex Spring) K. Schum) cultivados em sistema agroflorestal e em monocultivo na Amazônia Central, em duas épocas do ano, e também identificar características anatômicas da formação dessa simbiose nessas espécies. Foram realizadas coletas de solo e raízes em duas estações, seca e chuvosa. A colonização micorrízica arbuscular no cupuaçu e na pupunha é alterada pelo sistema de manejo adotado, com taxas maiores de colonização no monocultivo. A densidade total dos esporos de fungos micorrízicos arbusculares sob o cupuaçu não é alterada pelo sistema de manejo ou pela época do ano, ao contrário do que ocorre sob a pupunha. Nessa cultura, a densidade de esporos foi maior sob sistema agroflorestal no período seco. A colonização micorrízica na pupunha apresenta dois padrões anatômicos, Paris e Arum, enquanto no cupuaçu ocorre o padrão Arum.
\end{abstract}

Termos para indexação: Bactris gasipaes, Theobroma grandiflorum, fungos micorrízicos arbusculares, simbiose, sistema de manejo de culturas.

\section{Arbuscular mycorrhiza in cupuaçu and peach palm cultivated in agroforestry and monoculture systems in the Central Amazon region}

\begin{abstract}
The objective of this work was to evaluate the arbuscular mycorrhizal colonization in peach palm (Bactris gasipaes Kunth) and cupuaçu (Theobroma grandiflorum (Willd ex Spring) K. Schum), in agroforestry systems and monoculture in the Central Amazon region, and to identify anatomic characteristics of mycorrhizal colonization in these species. Soil and root samples were collected in the field, in the dry and rainy season. Mycorrhizal root colonization of cupuaçu and peach palm is affected by the management systems, with higher colonization rates in the monoculture system. Total spore density of the arbuscular mycorrhizal fungi under cupuaçu is not affected by management systems or season, but under peach palm this variation is season dependent. Mycorrhizal colonization of Arum and Paris types occur in peach palm, and only Arum type occurs in cupuaçu.

Index terms: Bactris gasipaes, Theobroma grandiflorum, arbuscular mycorrhizal fungi, symbiosis, crop management system.
\end{abstract}

\section{Introdução}

Micorrizas arbusculares são associações simbióticas formadas entre fungos da ordem Glomales e raízes da maioria das plantas vasculares. O termo arbuscular decorre da formação, no interior do córtex radicular, de uma estrutura fúngica altamente dicotômica denominada arbúsculo, sítio de troca entre o fungo e a planta. Sob o ponto de vista anatômico, nas células do córtex pode haver formação de arbúsculos, típicos ou não, se a colonização fúngica for do tipo Arum ou Paris (Smith \&
Read, 1997). Essa associação simbiótica proporciona benefícios a plantas em condições de solos de baixa fertilidade (Moreira \& Siqueira, 2002), comuns nos trópicos e na Amazônia Central.

O estabelecimento e o estádio da simbiose micorrízica podem ser afetados pelo manejo adotado no agrossistema (Smith \& Read, 1997; Moreira \& Siqueira, 2002). Sistemas de baixos insumos, cultivo mínimo, adição de matéria orgânica e diversificação de hospedeiro mediante rotação de culturas podem aumentar a colonização micorrízica (Miller \& Jackson, 1998; Galvez et al., 2001). 
O cupuaçu e a pupunha são espécies perenes de origem amazônica, cujo cultivo em sistemas agroflorestais ou em áreas de monocultivo vem se intensificando, num processo de transformação da exploração extrativista na agricultura. Apesar do registro da formação de micorrizas arbusculares nessas espécies, dados de caracterização anatômica da colonização não são conhecidos. Além disso, estudos da dinâmica da colonização micorrízica sob efeito dos sistemas de manejo dessas culturas são escassos no Brasil, especialmente na Amazônia (Bovi et al., 2000; Oliveira \& Oliveira, 2004).

O objetivo deste trabalho foi avaliar a colonização micorrízica arbuscular em pupunha (Bactris gasipaes Kunth) e cupuaçu (Theobroma grandiflorum (Willd ex Spring) K. Schum), quando cultivados em sistema agroflorestal e em monocultivo na Amazônia Central, em duas épocas do ano, além de identificar características anatômicas da formação dessa simbiose nessas espécies.

\section{Material e Métodos}

O trabalho foi desenvolvido na Embrapa Amazônia Ocidental, a $3^{\circ} 8^{\prime} \mathrm{S}, 59^{\circ} 52^{\prime} \mathrm{W}$, e $40-50 \mathrm{~m}$ de altitude, entre 2002 e 2003. A região de Manaus possui clima tropical chuvoso, sem estação seca (Af), segundo classificação de Köppen, caracterizado por temperatura média do ar de $26^{\circ} \mathrm{C}$, umidade relativa de $85 \%$ e regime pluviométrico com média anual de $2.600 \mathrm{~mm}$, e estações bem definidas. Os meses mais chuvosos (fevereiro e março) registram médias de aproximadamente $320 \mathrm{~mm}$, e os mais secos (agosto e setembro), pouco acima de $60 \mathrm{~mm}$ (Embrapa, 1997).

O solo é classificado como Latossolo Amarelo muito argiloso, com teor de argila, no horizonte superficial, em torno de $80 \%$, bem estruturado e originalmente ácido, com baixa capacidade de troca de cátions e baixos teores de fósforo.

Amostras de solo rizosférico e raízes de pupunha e cupuaçu, e do solo das entrelinhas, foram coletadas num experimento de longa duração, instalado em 1993, numa área de 13 ha. O delineamento experimental utilizado foi o de blocos ao acaso, com três repetições, e as parcelas mediam 48x32 m. As avaliações foram realizadas em amostras coletadas no sistema agroflorestal (SAF) composto de seringueira (Hevea brasiliensis (Willd. Ex A. Juss.) Müll. Arg.), pupunheira - manejada para utilização do palmito ou do fruto - e cupuaçuzeiro, e nos monocultivos de cupuaçuzeiro e pupunheira. No SAF, além das espécies arbóreas perenes, foi cultivado mamão (Carica papaya L.) nas entrelinhas, nos primeiros dois anos de cultivo. Os espaçamentos nos monocultivos de cupuaçu e pupunha foram de 7,0x6,4 e de 2,0x2,0 m, respectivamente. No SAF, o espaçamento entre linhas de cada espécie foi de $5 \mathrm{~m}$ e entre plantas, na linha, foi o mesmo adotado nos respectivos monocultivos.

No monocultivo de pupunha, as adubações no plantio foram realizadas nas doses (g por planta): $\mathrm{N}$ (uréia), 65, $\mathrm{P}_{2} \mathrm{O}_{5}$ (superfosfato triplo), 60; $\mathrm{K}_{2} \mathrm{O}(\mathrm{KCl}), 111$; bórax (8\% B), 1; e calcário dolomítico, 200. As doses de cobertura (g por planta) variaram ao longo dos anos: $\mathrm{N}$ (uréia ou sulfato de amônio), 36-112; $\mathrm{P}_{2} \mathrm{O}_{5}$ (superfosfato triplo ou atifós), $10-45 ; \mathrm{K}_{2} \mathrm{O}(\mathrm{KCl})$, 30-130; bórax (11\% B), 0-33; e FTE BR-12 (9\% Zn, $1,8 \% \mathrm{~B}, 0,8 \% \mathrm{Cu}, 3 \% \mathrm{Fe}, 2 \% \mathrm{Mn}$ e $0,1 \% \mathrm{Mo}$ ), $0-20$. No monocultivo de cupuaçu, as doses (g por planta) aplicadas no plantio, foram: $\mathrm{N}$ (uréia), 25; $\mathrm{P}_{2} \mathrm{O}_{5}$ (superfosfato triplo), 57; $\mathrm{K}_{2} \mathrm{O}(\mathrm{KCl}), 66$; MgO $\left(\mathrm{MgSO}_{4}\right), 3$; bórax (8\% B), 5; e calcário dolomítico, 500. As doses de cobertura (g por planta) também variaram ao longo dos anos: $\mathrm{N}$ (uréia ou sulfato de amônio), 29-83; $\mathrm{P}_{2} \mathrm{O}_{5}$ (superfosfato triplo ou atifós), 51-157; $\mathrm{K}_{2} \mathrm{O}(\mathrm{KCl}), 30-150$; bórax (11\% B), 0-2; e FTE BR-12 (9\% Zn, 1,8\% B, 0,8\% Cu, 3\% Fe, $2 \% \mathrm{Mn}$ e $0,1 \% \mathrm{Mo}), 0-50$. No SAF, foram aplicados fertilizantes correspondentes a $1 / 3$ da dose aplicada a cada espécie no monocultivo.

As coletas foram realizadas nas estações seca e chuvosa. Além do regime pluviométrico do período, levouse em consideração também a fenologia do cupuaçu, cuja frutificação ocorre na estação chuvosa. A primeira coleta (estação seca) foi realizada na entressafra do cupuaçu, no final de julho de 2002, e a segunda (estação chuvosa), durante a safra de cupuaçu, foi realizada em meados de maio de 2003.

Foram coletadas três amostras por parcela em cada espécie, nos dois sistemas de manejo, a 0,1 $\mathrm{m}$ de profundidade, com aproximadamente $0,6 \mathrm{~kg}$ de solo e raízes. As amostras foram compostas de quatro subamostras, coletadas sob a projeção da copa de cada planta e distribuídas aleatoriamente a cerca de $0,5 \mathrm{~m}$ do colo da planta. Além das amostragens sob as árvores, foram realizadas coletas nas entrelinhas. As amostras das entrelinhas foram coletadas na maior distância das árvores no monocultivo de pupunha e SAF, ao passo que no monocultivo de cupuaçu, coletaram-se amostras na mesma distância do SAF (2,5 m das árvores). 
Nas amostras de solo, as características químicas foram avaliadas de acordo com Silva (1999) e, na determinação da densidade de esporos de fungos micorrízicos arbusculares (FMA), foi empregada a técnica de peneiramento úmido (Gerdemann \& Nicolson, 1963) e centrifugação em sacarose (Jenkins, 1964) a partir de $50 \mathrm{~cm}^{-3}$ de solo. As raízes de pupunha e cupuaçu foram clarificadas e coloridas de acordo com Vierheilig et al. (1998), para determinar a colonização micorrízica. A porcentagem de colonização no cupuaçu foi estimada pelo método da placa quadriculada, em microscópio estereoscópico (Giovannetti \& Mosse, 1980), enquanto na pupunha, 80 segmentos de raízes com $1 \mathrm{~cm}$ de comprimento foram observados em microscópio óptico (aumento de 100 vezes).

Os resultados foram testados quanto à homogeneidade de variância e submetidos às transformações pertinentes. A análise de variância, com a aplicação do teste de médias de Tukey, ou teste $t$ de Student, a 5\% de probabilidade para os fatores ou desdobramentos das interações significativas, foi realizada por meio do procedimento GLM, do SAS. Foram feitas análises de correlação simples entre variáveis por meio do procedimento CORR, empregando-se o coeficiente de correlação de Pearson (SAS Institute, 1991).

\section{Resultados e Discussão}

Apesar das diferenças entre os sistemas de manejo e a posição das coletas, o solo da camada superficial dessas áreas em geral foi ácido, com elevado teor de matéria orgânica (MO), baixos teores de bases trocáveis e saturação por bases trocáveis e elevada acidez potencial (Tabela 1).

No SAF, não ocorreram diferenças na maioria das características químicas do solo sob o cupuaçu, a pupunha e nas entrelinhas, à exceção do pH e da CTC na estação seca. Nessa estação, constatou-se solo mais ácido sob o cupuaçu e a pupunha do que nas entrelinhas de cultivo (Tabela 1). Por sua vez, a CTC foi mais elevada sob o cupuaçu do que sob a pupunha e nas entrelinhas, o que pode estar relacionado à diferença na qualidade da serapilheira de cupuaçu e de pupunha (Uguen et al., 2002).

Os teores de P, nas estações seca e chuvosa, e de K, na estação chuvosa, foram maiores sob a pupunha

Tabela 1. Características químicas do solo nas entrelinhas, no cupuaçu e na pupunha, nos monocultivos e no sistema agroflorestal, nas estações seca e $\operatorname{chuvosa}^{(1)}$.

\begin{tabular}{|c|c|c|c|c|c|c|c|}
\hline \multirow[t]{2}{*}{ Parâmetro } & \multicolumn{2}{|c|}{ Monocultivo } & \multicolumn{2}{|c|}{ Monocultivo } & \multicolumn{3}{|c|}{ Sistema agroflorestal } \\
\hline & Cupuaçu & Entrelinhas & Pupunha & Entrelinhas & Cupuaçu & Entrelinhas & Pupunha \\
\hline & \multicolumn{7}{|c|}{ Estação seca } \\
\hline $\mathrm{MO}\left(\mathrm{g} \mathrm{kg}^{-1}\right)$ & $47,90 \mathrm{a}$ & $42,10 \mathrm{a}$ & $43,30 \mathrm{a}$ & $43,40 \mathrm{a}$ & $45,00 \mathrm{a}$ & $43,40 \mathrm{a}$ & $41,80 \mathrm{a}$ \\
\hline $\mathrm{pH}\left(\mathrm{H}_{2} \mathrm{O}\right)$ & $4,24 a b$ & $4,16 a b$ & $4,24 \mathrm{ab}$ & $4,44 a b$ & $3,95 b$ & $4,57 \mathrm{a}$ & $4,00 \mathrm{~b}$ \\
\hline $\mathrm{P}\left(\mathrm{mg} \mathrm{dm}^{-3}\right)$ & $73,55 \mathrm{a}$ & $4,44 \mathrm{c}$ & $38,55 b$ & $6,89 \mathrm{c}$ & $10,67 \mathrm{c}$ & $8,77 \mathrm{c}$ & $8,44 \mathrm{c}$ \\
\hline $\mathrm{K}^{+}\left(\mathrm{mmol}_{\mathrm{c}} \mathrm{dm}^{-3}\right)$ & $0,79 \mathrm{bcd}$ & $0,94 \mathrm{bc}$ & $1,32 \mathrm{a}$ & $1,06 \mathrm{ab}$ & $0,64 \mathrm{~cd}$ & $0,49 d$ & $0,68 \mathrm{~cd}$ \\
\hline $\mathrm{Ca}^{2+}\left(\mathrm{mmol}_{\mathrm{c}} \mathrm{dm}^{-3}\right)$ & $9,72 \mathrm{a}$ & $5,61 \mathrm{bc}$ & $5,86 \mathrm{bc}$ & $6,57 \mathrm{ab}$ & $3,33 \mathrm{bc}$ & $2,77 \mathrm{bc}$ & $2,38 \mathrm{c}$ \\
\hline $\mathrm{Mg}^{2+}\left(\mathrm{mmol}_{\mathrm{c}} \mathrm{dm}^{-3}\right)$ & $2,12 \mathrm{bc}$ & $3,39 \mathrm{ab}$ & $2,81 \mathrm{ab}$ & $3,88 \mathrm{a}$ & $1,13 \mathrm{c}$ & $2,34 \mathrm{bc}$ & $1,10 \mathrm{c}$ \\
\hline $\mathrm{Al}^{3+}\left(\mathrm{mmol}_{\mathrm{c}} \mathrm{dm}^{-3}\right)$ & $10,20 b$ & $10,20 b$ & $9,90 b$ & $8,10 b$ & $15,90 \mathrm{a}$ & $14,70 \mathrm{a}$ & $14,80 \mathrm{a}$ \\
\hline $\mathrm{H}^{+}+\mathrm{Al}^{3+}\left(\mathrm{mmol}_{\mathrm{c}} \mathrm{dm}^{-3}\right)$ & $92,90 \mathrm{ab}$ & $80,30 \mathrm{ab}$ & $84,70 \mathrm{ab}$ & $74,70 \mathrm{~b}$ & $95,00 \mathrm{a}$ & $75,00 \mathrm{~b}$ & $81,20 \mathrm{ab}$ \\
\hline $\mathrm{S}\left(\mathrm{mmol}_{\mathrm{c}} \mathrm{dm}^{-3}\right)$ & $12,60 \mathrm{a}$ & $9,90 \mathrm{ab}$ & $10,00 \mathrm{ab}$ & $11,50 \mathrm{a}$ & $5,10 \mathrm{c}$ & $5,60 \mathrm{bc}$ & $4,20 \mathrm{c}$ \\
\hline $\mathrm{CTC}\left(\mathrm{mmol}_{\mathrm{c}} \mathrm{dm}^{-3}\right)$ & $116,00 \mathrm{a}$ & $100,00 \mathrm{ab}$ & $105,00 \mathrm{ab}$ & $94,00 \mathrm{~b}$ & $116,00 \mathrm{a}$ & $95,00 \mathrm{~b}$ & $100,00 \mathrm{ab}$ \\
\hline \multirow[t]{2}{*}{$\mathrm{V}(\%)$} & $11,00 \mathrm{ab}$ & $10,30 \mathrm{abc}$ & $9,80 \mathrm{abcd}$ & $12,80 \mathrm{a}$ & $4,40 \mathrm{~cd}$ & $6,60 \mathrm{bcd}$ & $4,20 \mathrm{~d}$ \\
\hline & \multicolumn{7}{|c|}{ Estação chuvosa } \\
\hline MO $\left(\mathrm{g} \mathrm{kg}^{-1}\right)$ & $43,13 \mathrm{abc}$ & $45,61 \mathrm{ab}$ & $47,20 \mathrm{a}$ & $46,03 \mathrm{ab}$ & $40,33 \mathrm{bc}$ & $40,30 \mathrm{bc}$ & $38,76 \mathrm{c}$ \\
\hline $\mathrm{pH}\left(\mathrm{H}_{2} \mathrm{O}\right)$ & $4,34 \mathrm{abc}$ & $4,09 \mathrm{bc}$ & $4,54 \mathrm{a}$ & $4,52 \mathrm{a}$ & $3,98 \mathrm{c}$ & $4,45 \mathrm{ab}$ & $4,08 \mathrm{c}$ \\
\hline $\mathrm{P}\left(\mathrm{mg} \mathrm{dm}^{-3}\right)$ & $58,56 \mathrm{a}$ & $4,89 \mathrm{c}$ & $22,67 b$ & $10,44 c$ & $9,33 c$ & $6,78 \mathrm{c}$ & $6,67 \mathrm{c}$ \\
\hline $\mathrm{K}^{+}\left(\mathrm{mmol}_{\mathrm{c}} \mathrm{dm}^{-3}\right)$ & $0,74 \mathrm{bc}$ & $0,79 b c$ & $1,45 \mathrm{a}$ & $0,97 b$ & $0,66 \mathrm{c}$ & $0,50 \mathrm{c}$ & $0,72 \mathrm{bc}$ \\
\hline $\mathrm{Ca}^{2+}\left(\mathrm{mmol}_{\mathrm{c}} \mathrm{dm}^{-3}\right)$ & $12,36 \mathrm{a}$ & $5,59 b c$ & $10,10 \mathrm{ab}$ & $7,97 \mathrm{ab}$ & $3,11 \mathrm{c}$ & $3,12 \mathrm{c}$ & $2,06 \mathrm{c}$ \\
\hline $\mathrm{Mg}^{2+}\left(\mathrm{mmol}_{\mathrm{c}} \mathrm{dm}^{-3}\right)$ & $2,42 b c$ & $2,56 b c$ & $4,79 \mathrm{a}$ & $4,12 \mathrm{ab}$ & $1,24 \mathrm{c}$ & $2,30 \mathrm{bc}$ & $1,08 \mathrm{c}$ \\
\hline $\mathrm{Al}^{3+}\left(\mathrm{mmolc} \mathrm{dm}^{-3}\right)$ & $8,89 \mathrm{bcd}$ & $12,20 \mathrm{ab}$ & $6,81 \mathrm{~d}$ & $7,80 \mathrm{~cd}$ & $15,23 a$ & $11,91 \mathrm{abc}$ & $13,62 \mathrm{a}$ \\
\hline $\mathrm{H}^{+}+\mathrm{Al}^{+}\left(\mathrm{mmol}_{\mathrm{c}} \mathrm{dm}^{-3}\right)$ & $82,92 \mathrm{ab}$ & $87,84 a$ & $81,83 \mathrm{ab}$ & $77,65 \mathrm{ab}$ & $82,36 \mathrm{ab}$ & $69,75 b$ & $75,94 \mathrm{ab}$ \\
\hline $\mathrm{S}\left(\mathrm{mmol}_{\mathrm{c}} \mathrm{dm}^{-3}\right)$ & $15,51 \mathrm{a}$ & $8,93 \mathrm{bc}$ & $16,34 \mathrm{a}$ & $13,06 \mathrm{ab}$ & $5,01 \mathrm{c}$ & $5,92 \mathrm{c}$ & $3,85 \mathrm{c}$ \\
\hline $\mathrm{CTC}\left(\mathrm{mmol}_{\mathrm{c}} \mathrm{dm}^{-3}\right)$ & $98,43 \mathrm{a}$ & $96,77 \mathrm{a}$ & $98,17 \mathrm{a}$ & $90,71 \mathrm{ab}$ & $87,37 \mathrm{abc}$ & $75,67 \mathrm{c}$ & $79,79 \mathrm{bc}$ \\
\hline $\mathrm{V}(\%)$ & $15,24 \mathrm{ab}$ & $9,21 \mathrm{bc}$ & $16,77 \mathrm{a}$ & $14,71 \mathrm{ab}$ & $5,62 \mathrm{c}$ & $8,50 \mathrm{c}$ & $4,88 \mathrm{c}$ \\
\hline
\end{tabular}

(1)Médias seguidas da mesma letra, na linha, não diferem entre si pelo teste de Tukey a 5\% de probabilidade. 
cultivada em monocultivo do que na sua respectiva entrelinha. Sob cupuaçu em monocultivo, também houve maiores teores de $\mathrm{P}$ e Ca nas duas estações, quando comparado às entrelinhas. Os teores de $\mathrm{P}$ no solo diferiram entre os sistemas de manejo em ambas as espécies, nas duas estações, com os monocultivos apresentando valores maiores. Também houve diferenças nesses teores entre o cupuaçu e a pupunha, quando cultivados em monocultivos, porém, isso não ocorreu no SAF. Nos monocultivos, também foram registrados menores teores de $\mathrm{P}$ na entrelinha, em ambas as espécies (Tabela 1).

As principais diferenças entre os pontos amostrados foram verificadas nas linhas e entrelinhas dos sistemas de monocultivo e entre os sistemas de manejo numa mesma espécie. Isto reflete diferenças de quantidade de adubos minerais que vem sendo aplicada nos dois sistemas de manejo nos nove anos de cultivo.

Alterações na fertilidade do solo entre níveis diferentes de adubação em SAF, semelhantes às constatadas neste trabalho, foram observadas por Schroth et al. (2000). Apesar de não terem sido realizadas adubações durante o ano de coleta, o efeito residual das adubações anteriores pôde ser observado principalmente com relação ao P, nas duas espécies, e ao Ca em cupuaçu. No caso do P, sua baixa mobilidade proporciona maior tempo de permanência nos sistemas. Em relação ao Ca, o efeito residual só foi observado sob o cupuaçu. Isto pode estar relacionado à menor taxa de escorrimento de tronco observada nessa espécie quando comparada à pupunha (Schroth et al., 1999), o que implicaria em menor fluxo de água na área próxima ao colo da planta e reduziria as perdas de Ca por lixiviação. Além disso, a serapilheira de cupuaçu é mais rica em Ca (Uguen et al., 2002), o que pode ter refletido maiores taxas no sistema.

A densidade total de esporos de FMA sob o cupuaçu variou de 42-120 esporos por $50 \mathrm{~cm}^{3}$ de solo, porém essa variação não foi significativa nos dois sistemas de manejo e nas estações. Sob a pupunha, a densidade total de esporos de FMA foi de 27-48 esporos por $50 \mathrm{~cm}^{3}$ de solo e não sofreu efeito dos fatores sistema de manejo e época do ano isoladamente, mas houve efeito da interação entre esses dois fatores. Na estação seca, a densidade total de esporos no SAF foi superior (48 esporos por $50 \mathrm{~cm}^{3}$ de solo) ao sistema de monocultivo (27 esporos por $50 \mathrm{~cm}^{3}$ de solo). Na estação chuvosa, não houve diferença entre o SAF e o monocultivo.

Nas raízes de pupunha e de cupuaçu, foi possível visualizar e identificar várias estruturas de FMA. Na pupunha, identificou-se, nas células da epiderme, a for- mação de apressórios, esporos na superfície das raízes, ao passo que, no interior das células corticais, verificouse a formação tanto de arbúsculos típicos quanto de hifas enoveladas ou pelotões. Quanto ao cupuaçu, a colonização micorrízica foi caracterizada pelo crescimento de hifa intercelular e intracelular, com formação de arbúsculos no interior de células adjacentes. No entanto, não foi observada a formação de hifas enoveladas ou pelotões no interior das células.

De acordo com Smith \& Read (1997), a presença de arbúsculos típicos, resultante da intensa ramificação dicotômica, no interior das células do córtex do hospedeiro, é característica de colonização Arum, enquanto a presença abundante de pelotões e hifas enoveladas, no interior das células do córtex, é característica do padrão de colonização Paris. Portanto, nas raízes de pupunha, os padrões de colonização Arum e Paris podem estar ocorrendo simultaneamente. No cupuaçu, o padrão de colonização enquadrou-se como Arum, embora tenha sido registrada, na sua família (Sterculiaceae), a classe intermediária entre Arum e Paris (Smith \& Smith, 1997).

A observação simultânea dos dois tipos de padrão de colonização micorrízica - Arum e Paris - contraria Smith \& Smith (1997), que propõem apenas um tipo de padrão de colonização por espécie, o qual seria característico do grupo taxonômico do hospedeiro. Contudo, é razoável supor a ocorrência de mais de um tipo de padrão de colonização nas condições deste trabalho, considerando que o tipo de colonização é influenciado pela identidade do fungo simbionte, segundo Cavagnaro et al. (2001). Conforme indicam os dados de ocorrência de fungos baseados nos esporos presentes na rizosfera (Silva Júnior, 2004), pode haver mais de uma espécie de fungo colonizando as raízes.

Nas duas espécies, a colonização micorrízica foi afetada pela estação do ano e pelo sistema de manejo, porém não ocorreu interação entre esses fatores (Tabela 2). No cupuaçu, a maior colonização micorrízica foi

Tabela 2. Colonização micorrízica (\%) de cupuaçu e pupunha nas estações seca e chuvosa, e nos sistemas de cultivo(1).

\begin{tabular}{lrc}
\hline Parâmetro & Cupuaçu & Pupunha \\
\hline Estação & & \\
Seca & $7,19 \mathrm{~b}$ & $43,95 \mathrm{a}$ \\
Chuvosa & $21,93 \mathrm{a}$ & $13,54 \mathrm{~b}$ \\
\hline Sistema de cultivo & & \\
Monocultivo & $17,21 \mathrm{a}$ & $32,95 \mathrm{a}$ \\
Sistema agroflorestal & $13,41 \mathrm{~b}$ & $27,27 \mathrm{a}$ \\
\hline
\end{tabular}

${ }^{(1)}$ Médias seguidas de mesma letra, dentro de espécies e fator, não diferem entre si pelo teste de Tukey a 5\% de probabilidade. 
observada na estação chuvosa, enquanto na pupunha foi maior na estação seca. Os valores estão próximos dos observados por Oliveira \& Oliveira (2004), no cupuaçu, e por Bovi et al. (2000) na pupunha, cultivados em campo.

A diferença dos padrões sazonais da colonização entre o cupuaçu e a pupunha indica que fatores determinantes da sazonalidade da colonização micorrízica dessas espécies podem ser distintos. Allen et al. (1998), em estudo realizado nos trópicos mexicanos, também observaram, em espécies florestais, taxas maiores de colonização na estação chuvosa. Contudo, os autores relacionaram tal característica à maior atividade radicular nessa época do ano, na maioria das espécies estudadas.

O padrão sazonal da pupunha diferiu daquele observado no cupuaçu (Tabela 2). Isto, porém, não contraria a maior atividade da raiz na estação chuvosa, como o mecanismo de regulação que atuou no cupuaçu. Maior atividade das raízes da pupunha pode estar ocorrendo na estação seca, quando também se verifica maior crescimento da parte aérea (Moraes, 2002). Esse autor verificou aumento do perfilhamento, emissão de folhas e uma estreita relação da produção de pupunha decorrente do aumento da radiação solar nas condições climáticas da Amazônia Central. Devido à nebulosidade existente na estação chuvosa, o índice de radiação solar nessa região é maior na estação seca (Embrapa, 1997).

Tanto no cupuaçu quanto na pupunha, a colonização micorrízica foi maior nos monocultivos, independentemente da época de coleta (Tabela 2). No monocultivo, a porcentagem de colonização foi 28 e $21 \%$ superior aos valores observados no SAF, para o cupuaçu e a pupunha, respectivamente. A colonização micorrízica da pupunha apresentou correlação positiva com o P disponível $(\mathrm{r}=0,34, \mathrm{p}<0,05)$. No cupuaçu, a colonização micorrízica foi positivamente correlacionada com a soma de bases $(\mathrm{r}=0,36, \mathrm{p}<0,05)$ e a saturação por bases $(\mathrm{r}=0,44$, $\mathrm{p}<0,01)$, e negativamente com a CTC $(r=-0,45$, $\mathrm{p}<0,001)$, a acidez potencial $(\mathrm{r}=-0,36, \mathrm{p}<0,05)$ e o alumínio trocável $(\mathrm{r}=-0,47, \mathrm{p}<0,01)$.

Esses resultados demonstram que o manejo pode alterar o estabelecimento e a extensão da simbiose micorrízica, como constatado com outras espécies de plantas (Fernandes \& Siqueira, 1989; Kabir et al., 1997; Miller \& Jackson, 1998; Galvez et al., 2001; Feldmann et al., 2002) e mais especificamente na pupunha (Bovi et al., 2000).
Quando se avaliam sistemas de manejo, são muitos os fatores que podem estar atuando, relacionados ao preparo do solo, adubação, espaçamento e distribuição das plantas, controle das pragas e doenças, vegetação espontânea e outros.

Os sistemas de manejo avaliados são contrastantes sob dois aspectos principais: a composição, a distribuição e o espaçamento das espécies de plantas e a adubação. Inferências podem ser realizadas a partir dessas características e do conhecimento sobre a simbiose micorrízica arbuscular. Os monocultivos caracterizamse por sistemas em que o cupuaçu e a pupunha possuem maior disponibilidade de luz do que no SAF. Em condições controladas, a intensidade luminosa tem apresentado efeito regulador sobre a colonização micorrízica. Aumentos da disponibilidade de luz têm resultado em maiores taxas de colonização (Smith \& Read, 1997). No entanto, com base nos dados deste estudo, não é possível concluir se esse seria o mecanismo mais importante no efeito que o sistema de monocultivo apresentou sobre a colonização da pupunha e do cupuaçu, pois esses sistemas podem apresentar microclimas distintos, incluindo umidade do solo e do ar.

Fatores edáficos têm sido exaustivamente discutidos como reguladores da simbiose micorrízica arbuscular (Smith \& Read, 1997; Moreira \& Siqueira, 2002). Entre esses fatores, a disponibilidade de $\mathrm{P}$ no solo tem sido reportada como um dos mais comuns. Embora altos teores de P disponível reduzam a colonização micorrízica, doses intermediárias podem exercer efeito positivo (Bressan et al., 2001; Singh et al., 2002). No caso da pupunha, algumas evidências apontam para o envolvimento do $\mathrm{P}$ na determinação da maior taxa de colonização observada no monocultivo: há maior disponibilidade de P no monocultivo quando comparado ao SAF e há correlação positiva entre colonização micorrízica arbuscular e P disponível no solo $(r=0,34$, $\mathrm{p}<0,05)$. A regulação da colonização micorrízica arbuscular intermediada pelo $\mathrm{P}$ disponível no solo sob a pupunha é corroborada pelos dados de Bovi et al. (2000). Esses autores verificaram, em estudo realizado no campo com pupunha, que a colonização micorrízica foi favorecida por doses de $\mathrm{P}$ em torno de $100 \mathrm{~kg} \mathrm{ha}^{-1}$, num Neossolo Flúvico textura arenosa. Aumento da colonização micorrízica em virtude da adubação também já foi verificado por Feldmann et al. (2002) em seringueira, nas mesmas condições edafoclimáticas deste trabalho.

Pesq. agropec. bras., Brasília, v.41, n.5, p.819-825, maio 2006 
Em relação ao cupuaçu, a maior taxa de colonização micorrízica no monocultivo parece não estar relacionada à disponibilidade de P. Embora haja diferença nos teores de $\mathrm{P}$ no solo sob o cupuaçu, nos dois sistemas de manejo não foi observada, nessa espécie, correlação significativa entre colonização micorrízica e esse nutriente $(\mathrm{r}=0,21, \mathrm{p}<0,22)$. As evidências apontam para a participação da soma de bases e da saturação por bases no complexo de troca, na determinação do efeito do monocultivo de cupuaçu. A soma de bases e saturação por bases do complexo de troca do solo foram maiores sob cupuaçu cultivado em monocultivo, comparado ao cupuaçu em SAF (Tabela 1), e foram esses os parâmetros de solo que apresentaram correlação positiva com a taxa de colonização micorrízica do cupuaçu.

A colonização de cupuaçu apresentou correlação com vários parâmetros de solo que sofrem influência da calagem, tais como acidez potencial, soma de bases, saturação por bases e $\mathrm{Al}$ trocável. Essa resposta é fundamentada no efeito que a calagem exerce sobre a colonização micorrízica, observada por Lambais \& Cardoso (1988) e Saggin-Junior \& Siqueira (1996).

\section{Conclusões}

1. A colonização micorrízica arbuscular no cupuaçu e na pupunha é alterada pelo sistema de manejo adotado.

2. A dinâmica sazonal da colonização micorrízica arbuscular é diferente em cupuaçu e pupunha; a maior colonização micorrízica, no cupuaçu, ocorre na estação chuvosa, e na pupunha, na estação seca.

3. A densidade total dos esporos de fungos micorrízicos arbusculares sob o cupuaçu não é alterada pelo sistema de manejo ou pela época do ano, enquanto na pupunha há maior densidade total de esporos no sistema agroflorestal durante a estação seca.

4. Na pupunha, a colonização micorrízica apresenta dois padrões anatômicos - Paris e Arum -, ao passo que no cupuaçu ocorre apenas o padrão Arum.

\section{Agradecimentos}

Aos técnicos Denise de L. Colombo Mescolotti e Luís F. Baldesin, do Laboratório de Microbiologia do Solo da Esalq, pelo auxílio prestado; à Fundação de Amparo à Pesquisa do estado de São Paulo, pelo auxílio financeiro.

\section{Referências}

ALLEN, E.B.; RINCÓN, E.; ALLEN, M.F.; PÉREZ-JIMENEZ, A.; HUANTE, P. Disturbance and seasonal dynamics of mycorrhizae in a tropical deciduous forest in Mexico. Biotropica, v.30, p.261274, 1998.

BOVI, M.L.A.; TUCCI, M.L.S.; SPIERING, S.H.; GODOY JUNIOR, G.; LAMBAIS, M.R. Biomass accumulation and arbuscular mycorrhizal colonization in pejibaye (Bactris gasipaes Kunth) as a function of NPK fertilization. Acta Horticulturae, v.513, p.153167, 2000.

BRESSAN, W.; SIQUEIRA, J.O.; VASCONCELLOS, C.A.; PURCINO, A.A.C. Fungos micorrízicos e fósforo, no crescimento, nos teores de nutrientes e na produção do sorgo e soja consorciados. Pesquisa Agropecuária Brasileira, v.36, p.315-323, 2001.

CAVAGNARO, T.R.; GAO, L.-L.; SMITH, F.A.; SMITH, S.E. Morphology of arbuscular mycorrhizas is influenced by fungal identity. New Phytologist, v.151, p.469-476, 2001.

EMBRAPA. Centro de Pesquisa Agroflorestal da Amazônia Ocidental (Manaus, AM). Boletim agrometeorológico. Manaus, 1997. 19p.

FELDMANN, F.; SILVA JUNIOR, P.J. da; LIEBEREI, R. AMF spore community composition at natural and agricultural sites in Central Amazonia - a long term study. In: GERMAN-BRAZILIAN WORKSHOP ON NEOTROPICAL ECOSYSTEMS, 2000, Hamburg. Proceedings. Geesthacht: GKSS, 2002. p.669-682. Editores Reinhard Lieberei, Helmut K. Bianchi, Vera Boehm, Christoph Reisdorff.

FERNANDES, A.B.; SIQUEIRA, J.O. Micorrizas vesiculararbusculares em cafeeiros da região sul do Estado de Minas Gerais. Pesquisa Agropecuária Brasileira, v.24, p.1489-1498, 1989.

GALVEZ, L.; DOUDS, D.D.; DRINKWATER, L.E.; WAGONER, P. Effect of tillage and farming system upon VAM fungus populations and mycorrhizas and nutrient uptake of maize. Plant and Soil, v.228, p.299-308, 2001.

GERDEMANN, J.W.; NICOLSON, T.H. Spores of mycorrhizal Endogone species extracted from soil by wet sieving and decanting. Transactions of the British Mycological Society, v.46, p.235-244, 1963.

GIOVANNETTI, M.; MOSSE, B. An evaluation of techniques for measuring vesicular arbuscular mycorrhizal infection in roots. New Phytologist, v.84, p.489-500, 1980.

JENKINS, W.R. A rapid centrifugation technique for separating nematodes from soil. Plant Disease Reporter, v.48, p.692, 1964.

KABIR, Z.; O’HALLORAN, I.P.; FYLES, J.W.; HAMEL, C. Seasonal changes of arbuscular mycorrhizal fungi as affected by tillage practices and fertilization: hyphal density and mycorrhizal root colonization. Plant and Soil, v.192, p.285-293, 1997.

LAMBAIS, M.R.; CARDOSO, E.J.B.N. Avaliação da germinação de esporos de fungos micorrízicos vesículo-arbusculares e da colonização micorrízica de Stylosanthes guianensis em solo ácido e distrófico. Revista Brasileira de Ciência do Solo, v.12, p.249255, 1988. 
MILLER, R.L.; JACKSON, L.E. Survey of vesicular-arbuscular mycorrhizae in lettuce production in relation to management and soil factors. Journal of Agricultural Science, v.130, p.173-182, 1998.

MORAES, C.R. de A. Radiação solar, desenvolvimento e produção de palmitos de pupunha (Bactris gasipaes H.B.K.) em sistemas agroflorestais na Amazônia Ocidental. 2002. 86p. Tese (Doutorado) - Escola Superior de Agricultura Luiz de Queiroz, Piracicaba.

MOREIRA, F.M. de S.; SIQUEIRA, J.O. Microbiologia e bioquímica do solo. Lavras: Ufla, 2002. 626p.

OLIVEIRA, A.N.; OLIVEIRA, L.A. Associação micorrízica e teores de nutrientes nas folhas de cupuaçuzeiro (Theobroma grandiflorum) e guaranazeiro (Paullinia cupana) de um sistema agroflorestal em Manaus, Amazonas. Revista Brasileira de Ciência do Solo, v.28, p.1063-1068, 2004.

SAGGIN JUNIOR, O.; SIQUEIRA, J.O. Micorrizas arbusculares em cafeeiro. In: SIQUEIRA, J.O. (Ed.). Avanços em fundamentos e aplicação de micorrizas. Lavras: Ufla, 1996. p.203-254.

SAS INSTITUTE (Cary, Estados Unidos). Procedure guide for personal computers: release 6.11. $5^{\text {th }}$ ed. Cary, 1991. 649p.

SCHROTH, G.; SILVA, L.F. da; WOLF, M.A.; TEIXEIRA, W.G.; ZECH, W. Distribution of throughfall and stemflow in multi-strata agroforestry, perennial monoculture, fallow and primary forest in central Amazonia, Brazil. Hydrological Processes, v.13, p.14231436, 1999.

SCHROTH, G.; TEIXEIRA, W.G.; SEIXAS, R.; SILVA, L.F. da; SCHALLER, M.; MACÊDO, J.L.V.; ZECH, W. Effect of five tree crops and a cover crop in multi-strata agroforestry at two fertilization levels on soil fertility and soil solution chemistry in central Amazonia. Plant and Soil, v.221, p.143-156, 2000.

SILVA, F.C. da (Org.). Manual de análises químicas de solos, plantas e fertilizantes. Brasília: Embrapa-SCT, 1999. 370p.

SILVA JÚNIOR, J.P. da. Comunidades de fungos micorrízicos arbusculares associadas à pupunha e ao cupuaçu cultivados em sistema agroflorestal e em monocultivo na Amazônia Central. 2004. 95p. Tese (Doutorado) - Escola Superior de Agricultura Luiz de Queiroz, Piracicaba.

SINGH, C.; SHARMA, A.K.; JOHRI, B.N. Host genotype determines the impact of soil phosphorus on arbuscular mycorrhizal symbiosis in maize (Zea mays L.). Symbiosis, v.33, p.145-164, 2002.

SMITH, F.A.; SMITH, S.E. Structural diversity in (vesicular)arbuscular mycorrhizal symbioses. New Phytologist, v.137, p.373388, 1997.

SMITH, S.E.; READ, D.J. Mycorrhizal symbiosis. $2^{\text {nd }}$ ed. San Diego: Academic Press, 1997. 605p.

UGUEN, K.; BERNHARD-REVERSAT, F.; LUIZÃO, F.; SILVA, J.P.; SCHROTH, G. Nutrient fluxes from litter and prunings in an agroforestry system in central Amazonia. In: GERMANBRAZILIAN WORKSHOP ON NEOTROPICAL ECOSYSTEMS, 2000, Hamburg. Proceedings. Geesthacht: GKSS, 2002. p.851-853. Editores Reinhard Lieberei, Helmut K. Bianchi, Vera Boehm, Christoph Reisdorff.

VIERHEILIG, H.; COUGHLAN, A.P.; WYSS, U.; PICHÉ, Y. Ink and vinegar, a simple staining technique for arbuscular-mycorrhizal fungi. Applied and Environmental Microbiology, v.64, p.50045007, 1998.

$\overline{\text { Recebido em } 21 \text { de dezembro de } 2004 \text { e aprovado em } 6 \text { de janeiro de } 2006}$ 